\title{
A study on teaching mode of Flipped Classroom of Intersubjectivity in College Japanese Teaching
}

\author{
Wanyu Li \\ Foreign language Institude of XinXiang College, Xinxiang, Henan 453003
}

\begin{abstract}
Intersubjectivity education provides us with a theoretical guidance to exploring a new college Japanese teaching mode. Meanwhile, it provides a new perspective for the teaching reform. Based on the foreign language teaching theory connotation and the characteristics of intersubjectivity in college Japanese teaching, this article will discuss a new teaching mode under the guidance of intersubjectivity --Flipped Classroom. The Flipped Classroom teaching mode under the guidance of intersubjectivity not only can improve the students' learning enthusiasm and initiative, but also can cultivate students' innovation ability and practice ability.
\end{abstract}

Keywords: Intersubjectivity; College Japanese; Flipped classroom

\section{大学日语教学主体间性之 “翻转课堂” 教学模式}

\section{研究}

李万豫

(新乡学院外国语学院 河南 新乡 453003)

摘要: 主体间性的教育观为探索大学日语教学新模式提供了理论指导, 为教学改革提供了新的视野。本文从主体间性的 外语教学理论内涵、大学日语教学中的主体间性的特征, 探讨了主体间性理论指导下的大学日语教学新模式——“翻转课堂” 教学。认为主体间性理论指导下的“翻转课堂”教学新模式可以提高学生的学习积极性和主动性, 有利于培养学生的创新能力 和实践应用能力。

关键词: 主体间性; 大学日语; 翻转课堂

\section{引言}

在信息化时代下，众多高校的本科外语教学计划中都将第二外语作为必修课程设置，而很多高校又大 多选择日语作为第二外国语, 大学日语教学在高校应用广泛。但在教学中又存在诸多的问题, 如教学资源 的惯乏、学生重视程度不够、教学模式的单一等, 影响了教学。本文就大学日语的教学模式, 进行一定的 思考和建议。

\section{1 大学日语教学中主体间性的特征}

教学模式, 指在一定教育观念、教育理论和教学思想指导下建立起来的教学方式和教学活动结构。不 同的教育理论和教学思想, 形成不同类型的教学模式。在主体间性理论指导下, 大学日语教学也形成了不 同于其它学科的教学模式，它具有以下几方面的特征:

\section{1 平等性}

在教学活动中, “每一个教育主体都有参加和继续交往的相对均等机会, 都有表达愿望、感情、打算 的均等机会, 都必须有作出判断、劝告、解释以及向辩护挑战的均等机会”。当然, 在实际教学活动中, 无法做到 “完全均等”, 但是在教学活动中, 我们应该尊重学生的认知和情感世界, 大学日语主体间性教 
学的教学目的不仅仅是 “授业”、“解惑” 式的传授知识, 更多的是教会学生日语学习的方法和能力, 帮 助他们自助学习, 实现自我, 为将来的全面发展奠定好基础。

\section{2 受制性}

主体间性理论指导下的外语教学的前提是, 在教学中应重视对学生的学习积极性和主动性的调动, 鼓 励学生积极参与课堂教学活动, 但是在具体实施的时候, 作为主体的教师和学生的主体间性不是孤立存在 的, 它受师生所共有的教学客体制约, 是以所要学习的教学内容、使用的教材及所拥有的教学资源等为前 提的。所以，大学日语主体间性教学的所有活动都应围绕教学资源、教学环境等为基础来展开。

\section{3 交互性}

也就是我们所说的师生间的互动关系。由于大学日语教学对象几乎都是从零起点的学生, 在教学实践 中, 无论是单纯的语言基础知识的传授, 还是语言技能训练和培养, 甚至是日本文化知识的渗透, 在教学 活动中, 都需要引导学生主动参与, 实施师生互动。通过师生间在情感、观点、知识和对事物的认识等各 个方面的交流与互动, 双方在这种相互作用、相互影响、相互理解和认可的关系中不断重构自己已有的经 验、知识、观点、看法以及认识，建立一种协调的师生主体间性关系。

\section{4 发展性}

世界万物都是不断发展变化的。教学活动中交往的主体应本着发展的眼光，不断地对旧有的认识进行 内化、重构, 不断寻找新的突破点, 建构并超越以往的新内容。在教学过程中, 师生交往中一方的发展会 促进、带动另一方的发展。

\section{5 主动性}

在教学活动中, 作为交往主体的师生之间应积极主动地进行交往。教师要主动引导、启发并鼓励学生 进行主体间的交往, 以便扩大主体间的相互理解和了解, 从而改善教学效果, 提高教学质量, 最终实现培 养学生创新能力和实践应用能力的教学目标。

\section{2 “翻转课堂”下的大学日语教学模式}

根据主体间性教学模式的特征和我国现行教学行政班级的课堂特点, 要改变目前大学日语教学中存在 的主客对立现状, 变革单一的教学形式, 提高教学质量, 需要探究大学日语教学的新模式, 在教学实践中 可以从翻转课堂教学模式做一下尝试, 主要有以下几个方面。

\section{1 让学生进行独立的脑力劳动----研究性学习}

要使思维、思考成为名副其实的脑力劳动, 那就必须使思维具有明确的目的性, 也就是说, 要使它具 有解决任务的性质。

教师越是善于给学生的思维活动赋予一种解决任务的性质, 那么他们的智慧力量就越加积极地投入这 种活动，障碍和困难就暴露得越加明显，从而使脑力劳动成为一种克服困难的过程。

学生通过研究性的学习法去证明一个解释和推翻另一个解释，在这种情况下，知识就不是消极地掌握 的, 而是去获取的, 即靠积极的努力去获得的。因此, 这种知识就能变成信念, 学生也会更加的珍视它们。 充分发挥学生在教学活动中的主体作用，培养他们的参与意识。由于大学日语普遍存在的问题，即缺 乏学习氛围和学生重视度不够等, 造成学生学习大学日语的积极性、主动性缺乏, 学生不能积极主动地参 与学习, 在教学活动中他们总是处于被动学习的客体地位, 他们的主体地位无从谈起。在教学中就需要教 
师充分考虑学生的主体地位, 加强与学生的交流与互动, 在教学手段上采用传统教学与直观模拟教学相结 合的方式, 让学生更多地参与课堂教学活动, 调动学生的积极主动性, 确立他们的主体地位, 培养他们的 参与意识。

\section{2 教师要教会学生利用自由支配的时间}

给学生提供自由支配的时间, 并不是说让他们开小差, 玩手机, 闲聊等等, 放任自流会养成无所事事、 懒散疲塌的不良习气。要尽可能做到让有趣的、使学生感到惊奇的东西, 同时成为学生的智慧、情感和全 面发展所需要的, 必不可少的东西。日语文章的阅读也应当成为吸引学生爱好的重要的发源地, 要使知识 “活起来” , 应努力做到, 使知识既是最终目的, 又是获取新知识的手段或工具。教师要使知识在学生的 脑力劳动中、在集体的精神生活中、在学生之间的相互关系中活起来, 在急速发展的、经常不断的精神财 富的交流中活起来。

教师要转变教学观念, 调整自己在教学活动中的主体地位, 组织与学生双向互动的教学模式。信息化 时代的教学不再是老师教, 学生学的模式, 而是师生之间通过相互交流、相互沟通、相互作用、相互理解 的 “教” 与 “学” 的双向交流活动。当学生需要指导时, 教师成为学生便捷的获取利用教学资源, 理解处 理知识的脚手架。

培养和提高学生自主学习的意识和能力改变传统的教学模式，重新定位“教”与“学”。大学日语的 教学, 不是让学生掌握多少日语知识, 而是培养学生灵活运用日语这个 “工具” 的能力, 使他们成为适应 新形势要求的复合型外语人才。这就要求大学日语的教学应以学生为中心, 教师应该由单纯的知识传授者 转变为学生学习的组织者、指导者、参与者、合作者。教师负责组织教学, 确定教学内容, 引导学生发现 问题和解决问题, 调动学生的积极性和创造性, 激发他们的潜能, 培养学生自主学习的意识和能力。此外, 教师在教学中不仅要教给学生语言知识、语言技能, 还应该教给学生语言学习策略, 即要 “授之以渔”。 学习策略的使用不仅可以改进大学日语的学习方式, 提高学习效率, 减轻学习负担, 而且还有利于学生形 成自主学习能力和实现个性化学习, 有利于学生的身心健康。

\section{3 “翻转” 增加了学习中的互动}

翻转课堂最大的好处就是全面提升了课堂的互动，具体表现在教师和学生之间以及学生与学生之间。 由于教师的角色已经从内容的呈现者转变为学习的教练, 这让教师有时间与学生交谈, 回答学生的问题, 参与到学习小组, 对每个学生的学习进行个别指导。当学生在完成作业时, 教师会注意到部分学生为相同 的问题所困扰, 于是就组织这部分学生成立辅导小组, 往往会为这类有相同疑问的学生举行小型讲座。小 型讲座的美妙之处是当学生遇到难题准备请教时, 教师能及时的给予指导。

\section{3 建立灵活多样的教学方法体系}

调整教学目标, 建立灵活多样的教学方法体系。教学方法是保证教学活动顺利实施、师生交往顺利进 行、提高教学效果的主要手段之一。而教学方法可以通过调整教学目标来实现。在主体间性理论指导下, 课堂教学目标不再是单一的知识与技能, 而是 “知识与技能、过程与方法以及情感、态度与价值观三方面 的整合”。新的教学观认为教学不仅要获取知识和技能, 更要学会获取知识后形成正确的价值观, 以促进 个性的解放和发展。总之, 在大学日语教学活动中, 教师与学生的主体性都不容忽视, 师生双方互为主体, 共处于一个相互平等、相互融洽和相互理解的活动统一体中。 
现代外语教学把从以文法为中心转变为以会话为中心, 这是纠正以前过分强调文法教学的一种动向, 但绝不是说大学日语教学以会话为中心。支撑 “听、说、读、写” 四个基本能力的归根结底还是语法, 因 此, 从初级阶段开始, 必须注重语法和会话两者的有机结合。教师 “精讲”, 学生 “多练”, 正确处理好 “精讲” 与 “多练” 的关系。“精讲” 就是讲解要简明、扼要, 对所讲解的语言材料要深加工, 提炼出精 华，所选择的材料既要准确又要有利于交际能力的培养。而 “多练” ，在内容上要有针对性、目的性, 在 形式上要灵活、多样、趣味性强, 如此才能激发起学生的学习欲望、提高学习效率。

\section{4 结束语}

本文认真探讨的主体间性理论指导下的大学日语教学模式，充分考虑了教学活动中师生之间的这种关 系和作用。采取这种 “翻转课堂” 教学模式开展教学, 有利于激发学生的学习兴趣, 可以提高学生的学习 积极性和主动性, 能达到最佳的教学效果。

\section{4. 致谢}

新乡学院科技创新项目 “高校转型期英语专业二外日语教育的问题及对策”（编号：15SB33）

\section{Acknowledgement}

The Science and Technology Innovation Project of Xinxiang University_the Problems and Countermeasures of Japanese Education as the Second Language of English Majors（NO.15SB33）

\section{参考文献:}

[1] 田孝平. 关于高校日语 (第二外语) 教学方法和教学手段的思考[J]. 科技经济市场，2007，(01）:159-160.

[2] 韩冰, 江春华. 综合大学二外日语教育研究 [J]. 日语学习与研究, 2013, (8).

[3] 项桂芬, 吴丽丽, 罗晶. 情景+任务型教学法在日语二外教学中的应用模式探讨 $[J]$. 东华理工大学学报 (社会科学版), 2010,6 .

[4]张金否，王颖，张宝辉. 翻转课堂教学模式研究 [J]. 远程教育杂志，2012，4.

[5] 陈要勤, 陈华胜. 珠三角日语人才市场需求调研与专业人才培养策略 [J].广东外语外贸大学学报, 2011，9.

作者简介：李万豫，1972 年生，女，四川富顺（籍贯），讲师（职称），研究生 (学历), 研究方向：日本文化

\section{References:}

[1] Tian Xiaoping. Think about Teaching Methods and Means of the Second Foreign Language of College Japanese [J]. Science \& Technology Ecnony Market, 2007, (01): 159-160.

[2] HanBing, Jiang Chunhua. A study about the Second Foreign Language of Japanese in Comprehensive University [J]. Journal of Japanese Study and Research, 2013, (8).

[3] Xiang Guifen, Wu Lili, Luo Jing. An Exploration about Application mode Based on Scene+Task method in teaching the Second Foreign Language of Japanese [J]. Journal of East China University of Science and Technology (Social Science Edition), 2010, 6.

[4] Zhang Jinlei, Wang Ying, Zhang Baohui. Study of the Flipped Classroom Teaching Mode [J]. Journal of Distance Education, 2012, 4.

[5] Chen Yaoqin, Chen Huasheng. INvestigation about Market Demand of Japanese Talents and Training Strategy of Professional Talents in Pearl River Delta [J]. Journal of Guangdong University of Foreign Studies, 2011, 9.

About the Author: Li Wanyu, born in 1972, female, Sichuan Fushun (native place), lecturer (title), Postgraduate (degree), research direction: Japanese culture. 